\title{
O Significado das Tecnologias de Informação para Educadores
}

\author{
Christina Marília Teixeira da Silva \\ Nyrma Souza Nunes de Azevedo
}

\section{Resumo}

A pesquisa descrita, de natureza quanti-qualitativa, visou investigar as percepções de docentes em relação às tecnologias de informação (TI), em especial o computador e a Internet. Trata-se de continuação de estudo anterior, que buscou identificar o significado das TI para os educandos. Os dados obtidos junto a 556 alunos revelaram que estes, além de desejarem lidar com as $\mathrm{TI}$ em sua aprendizagem, consideravam o computador como uma ferramenta $e$, a Internet, um instrumento de comunicação e pesquisa.

Neste estudo, com 120 professores de escolas públicas e particulares, encontramos indicadores de o

Christina Marília
Teixeira da Silva
Dra. em Engenharia de
Produção, COPPE/UFRJ
Pesquisadora do
Laboratório do Imaginário
Social em Educação -
LISE/UFRJ
Nyrma Souza Nunes
de Azevedo
Dra. emEducação, Faculdade
de Educação/UFRJ
Profa. da Faculdade de
Educação/UFRJ e
Coordenadora do LISE

parte do magistério às novas tecnologias vem diminuindo.

Palavras-chave: Educação. Tecnologias de informação. Psicologia educacional.

\section{Introdução}

presente artigo apresenta o relato de pesquisa que teve por objetivo investigar as percepções de docentes em relação às tecnologias de informação (TI), em especial o computador e a Internet.

Em nossa experiência como educadoras, percebemos que a presença das novas tecnologias na educação não é vista da mesma maneira por educandos e educadores. Os alunos parecem encará-las com naturalidade tanto no ambiente de aprendizagem, quanto no seu dia-adia. Com relação aos professores, embora parte deles as utilize em suas vidas, o mesmo nem sempre é verdadeiro no caso de sua prática pedagógica (SILVA; AZEVEDO, 2001). 
Uma das possíveis conseqüências dessa diferença entre educadores e educandos, ao lidarem com as novas tecnologias na educação, é os alunos alcançarem autonomia e os professores ficarem, cada vez mais, marginalizados do processo de ensino-aprendizagem.

Pesquisa realizada pela Unesco em 2002, em nível nacional, envolvendo 5 mil docentes do ensino básico, que atuavam em escolas públicas e privadas, revelou que mais da metade dos professores brasileiros não possuía computador em casa, não utilizava a Internet, nem e-mail (MEDEIROS, 2004). Além disso, cerca de um terço dos docentes se autoclassificou como pobre, $65,5 \%$ tinham renda familiar entre dois e dez salários-mínimos e 36,6\% entre cinco e dez salários. Na faixa de mais de 20 salários, 91,7\% tinham computador na residência e $89,7 \%$ usavam a rede. Esses dados indicam que a exclusão digital está diretamente relacionada com a situação econômica dos professores. Jorge Werthein', representante da Unesco no Brasil, afirma: "Não há como um professor ensinar aos alunos como usar a informática a não ser que ele saiba. E não sabe nem o potencial nem como proteger os alunos do lado pernicioso da internet. É um absurdo". Ainda segundo a referida pesquisa, os professores reconheciam o potencial da Internet para a educação, mas não usavam computadores na prática pedagógica.

Em estudo anterior, em que buscamos identificar o significado das TI para os educandos (SILVA; AZEVEDO, 2003), observamos um alto percentual de atitudes favoráveis manifestadas pelos alunos das escolas públicas e particulares, evidenciando que estes desejavam lidar com o computador e a Internet em sua aprendizagem.

Outra observação relevante é que eles pareciam não temer tais tecnologias.
No entanto, verificamos que a realidade vivida pelos alunos das escolas públicas e particulares pesquisadas era bem diferente: os primeiros tinham acesso restrito e pouco conhecimento sobre tais tecnologias; os demais possuíam maior facilidade de acesso e maior conhecimento. Inclusive, parte considerável dos alunos das escolas públicas acreditava que o computador pudesse substituir os professores, o que não foi observado com os demais alunos.

Em todas as escolas, as funções mais associadas pelos alunos ao computador e à Internet foram, respectivamente, a de ferramenta e a de meio de comunicação. Uma das finalidades com que mais usavam a Internet era para realizar pesquisas solicitadas pelos professores. A utilização das tecnologias com outros fins, como diversão ou preparação para o mercado de trabaIho, foi mencionada por uma percentagem diminuta, o que nos causou surpresa.

$\bigcirc$ potencial das tecnologias de informação para a educação vem sendo discutido em publicações nacionais e estrangeiras, dentre as quais podemos citar: Alava e outros (2002), Almeida (2000), Battro e Denhan (1997), Franco (1997), Hackbarth (1997), Lévy (1993, 1999, 2002), Maddux (1994), Moran (1998, 2000), Oliveira (1997), Palloff e Pratt (2002), Perrenoud (2000), Silva (1997, 1999), Silva e Elliot (1997, 1998) e Valente (1998).

Um dos aspectos enfatizados por diferentes autores é a necessidade de mudança de paradigma, no sentido de se utilizar tais tecnologias de maneira a favorecer a construção do conhecimento, a cooperação, a negociação, a autonomia, a reflexão e a crítica. Dessa forma, muda o papel do professor, que deixa de ser um repassador de informações, para atuar como um mediador do processo, bem como incentivar seus alu- 
nos a serem mais independentes e responsáveis por sua própria aprendizagem.

Assim, acreditamos ser importante investigar o significado das TI para os educadores, no sentido de identificarmos quais são os fatores que podem estar dificultando, ou mesmo impedindo, os professores de usarem as tecnologias, de forma adequada e natural, em sintonia com os desejos e expectativas de seus alunos, aumentando, assim, a motivação e a participação dos educandos.

\section{Significado, Significação, Representação e Imaginário Social}

Em estudos anteriores (SILVA; AZEVEDO, 2001, 2003) enfatizamos a importância do significado para as ações humanas e sua dependência da cultura, entendida como o que molda os seres, adaptando-os às suas exigências, através principalmente da língua, vista como sistema simbólico compartilhado que possibilita a construção, a interpretação e a negociação de sentidos. A linguagem fornece os conceitos e as formas de organização da realidade que constituem a mediação entre o sujeito e o objeto do conhecimento (VYGOTSKY, 1987). Demos ênfase, também, aos conceitos relativos a crenças, desejos, intenções e compromissos, considerados instrumentos fundamentais, por serem os que dominam as transações da vida cotidiana.

É importante ressaltar que a abordagem sociocultural, que norteia esses trabalhos, concebe o ser humano como uma unidade indivisível onde não se separa corpo e mente, emoção e razão, pensamento e ação (WALLON, 1995).
Concepções consideradas atualmente, sobre a dinâmica dos processos cognitivos, especialmente no que se refere à construção de significados, são citadas por Machado (1995), que acredita ser possível a apreensão do significado de um objeto ou de um acontecimento por vê-lo em suas relações, articuladas em redes construídas social e individualmente, em permanente estado de atualização. As redes subsistem em um espaço de representações constituindo uma teia de significações. Os pontos ou nós destas redes são significados - de objetos, pessoas, lugares, proposições, teses, etc, ligados por relações, não subsistindo isoladamente, mas como pontes entre pontos. As relações englobam tanto as de natureza dedutiva, as dependências funcionais, as implicações causais, quanto as analogias ou certas influências e interações sincrônicas, que não podem ser situadas no âmbito da causalidade em sentido estrito.

Azevedo (2003), ao aprofundar a compreensão dessa teia da qual fazemos parte em nosso mundo cotidiano, encontra em Castoriadis (1991, p. 13) a afirmação de que a sociedade é constituída pelo imaginário social, considerado "criação incessante e essencialmente indeterminada (social-histórica e psíquica) de figuras, formas, imagens, a partir das quais somente é possível falar-se de 'alguma coisa'. Aquilo que denominamos 'realidade' e 'racionalidade' são seus produtos". Para a referida autora ${ }^{2}$, Castoriadis reduz à faculdade originária de pôrse ou dar-se, sob a forma de representação, uma coisa e uma relação que não são dadas na percepção ou nunca o foram; chegando a uma "capacidade elementar e irredutível de evocar uma imagem", tratandose, então, de uma imaginação radical.

\footnotetext{
MEDEIROS, 2004, p. 3.

${ }^{2}$ CASTORIADIS, 1991, p. 154 apud AZEVEDO, 2003
} 
Chama Castoriadis ${ }^{3}$ de imaginário radical o que emerge como social-histórico e como psiquê-soma: "Como social-histórico ele é corrente do coletivo anônimo; como psiquêsoma é fluxo representativo/ afetivo/ intencional". Denomina imaginário social ou sociedade instituinte a criação de significações imaginárias e institucionais, sendo a sociedade a instituição de um magma de significações que se instrumentaliza no fazer e representar/ dizer social, implicados reciprocamente.

suporte representativo participável dessas significações, ao qual elas não se reduzem, consiste em imagens ou figuras: fonemas, palavras, cédulas, estátuas, igrejas, instrumentos, uniformes, partituras musicais, mitos, etc, além da totalidade do percebido natural, designado ou designável pela sociedade considerada. É, enfim, a realidade como é percebida, além da possível. "O imaginário social é, primordialmente, criação de significações e criação de imagens ou figuras que são seu suporte" (CASTORIADIS, 1991, p. 277), e o simbólico é esta relação. Alertanos o autor que, salvo numa etapa de pensamento muito desenvolvido em que significante, significado e seu vínculo sui generis (sentido) são mantidos como unidos e distintos numa relação firme, mas flexível, em geral esta relação permanece ligada ao vínculo que the deu origem sob a forma de identificação, participação ou de causação.

Por outro lado, para Wallon (1995), o que o indivíduo aprende a exprimir e, por conseguinte, conhecer de seus desejos, não é senão o seu aspecto socializado. É todo um conjunto de noções, mesmo provisoriamente sem utilização nem aplicação pessoais, que ele adota, como moeda de troca necessária, ou mesmo eventualmente como modelo de ação (AZEVEDO, 2003). Em seu esforço por se co- nhecer, o indivíduo sabe aplicar a si mesmo uma opinião, cuja origem está tanto nele quanto fora, mas que lhe é imposta, como a todos os demais, pelo meio social e, através deste, pelas condições e formas atuais da existência social. A introspecção parte, não do indivíduo, mas do que não é próprio de ninguém, porque é obrigatório para todos (WALLON, 1995). Pode-se considerar, que o que é descrito como "opinião" extrapola o conceito de controle social, aproximando-se do conceito de representações sociais, como é entendido na Psicologia Social, por ser um instituinte mental e de ação, embora já instituído.

Os autores descritos fazem-nos refletir sobre a importância de serem desveladas as significações expressas nas representações dos sujeitos com os quais pretendemos atuar, principalmente no que diz respeito às formas pedagógicas. Com este estudo, almejamos investigar, como os professores significam a possibilidade de utilização das TI em sua vida profissional. Supomos que devido, tanto à rapidez com que as tecnologias vêm sendo implementadas/modificadas, quanto à sua presença, cada vez maior, em quase todas as esferas de atuação da sociedade, submetendo os indivíduos a um estado de dependência, as significações dos professores podem estar sendo transformadas rapidamente, tanto de forma favorável, quanto desfavorável, em relação à utilização pedagógica das TI.

\section{A Pesquisa \\ - Descrição e Resultados}

A pesquisa foi desenvolvida em quatro escolas, de ensino fundamental e médio, situadas no Rio de Janeiro, sendo três públicas (federal, estadual e municipal) e uma particular. $\bigcirc$ público-alvo foram os professores dessas escolas. Para a obtenção dos dados do estu-

${ }^{3}$ CASTORIADIS, 1991, p. 414. 
do foram empregados questionários. $\bigcirc$ questionário, adaptado de instrumento anteriormente validado (SILVA, 1997), foi aplicado a 120 professores no primeiro semestre de 2003 . O instrumento, composto de 13 questões fechadas e duas questões abertas, teve por objetivo identificar, no que se refere a computadores e Internet, atitudes, preconceitos, familiaridade, acesso, finalidades de uso e formas de emprego (ou não) na prática pedagógica. Seu modelo encontra-se no final do artigo (anexo).

\section{Resultados obtidos com a aplicação do questionário}

Os dados levantados a partir das questões fechadas (1 a 13) são apresentados nas Tabelas 1 a 4 . O tratamento das questões abertas (14 e 15) foi realizado por meio de Análise de Conteúdo (BARDIN, 1977) e os resultados encon- tram-se resumidos nos Quadros 1 a 4. A seguir, são comentados os dados obtidos em cada escola.

"Escola A (Federal): Atende a alunos do ensino fundamental e médio que provêm, em sua maioria, de famílias com renda média. A instituição está equipada com computadores/Internet que podem ser usados por professores e alunos. $\mathrm{Na}$ amostra, constituída de 22 professores, 14 eram do sexo feminino e suas idades variaram de 24 a 66 anos, sendo a idade média aproximadamente igual a 40 anos. $\bigcirc$ tempo de magistério variou de 1 a 48 anos, com maior concentração de professores com menos de 10 anos de experiência. A grande maioria possuía Mestrado ou Especialização. A maior parte atuava somente no Ensino Médio ou no Ensino Fundamental/Médio.

\section{Tabela 1. Resultados das Questões Fechadas do Questionário na Escola A ( $\mathbf{n = 2 2 )}$}

\begin{tabular}{|c|c|c|c|c|c|c|c|c|}
\hline Questão & & C & & C P & & D & & \\
\hline 1 & & 1 & & 5 & & 16 & & \\
\hline 2 & & - & & 4 & & 18 & & \\
\hline 3 & & 10 & & 10 & & 2 & & \\
\hline 4 & & 2 & & 13 & & 7 & & \\
\hline 5 & & 1 & & 10 & & 11 & & \\
\hline 6 & & - & & 4 & & 18 & & \\
\hline 7 & & 22 & & - & & - & & \\
\hline & SO & & ME & & SU & & NL & \\
\hline 8 & 4 & & 10 & & 8 & & - & \\
\hline & & S & & G & & ND & & \\
\hline 9 & & 20 & & 2 & & - & & \\
\hline 10 & & 21 & & 1 & & - & & \\
\hline & & NU & & AV & & M & & \\
\hline 11 & & 1 & & 8 & & 13 & & \\
\hline & & S & & N & & S R & & \\
\hline 12 & & 3 & & 18 & & 1 & & \\
\hline & B & P & J & E & V & NAV & O & S R \\
\hline 13 & 3 & 18 & - & 18 & 14 & 3 & 3 & 2 \\
\hline
\end{tabular}

Nota: C (concordo), CP (concordo em parte), D (discordo), SO (sólido), ME (mediano), SU (superficial), NL (nulo), S (sim), G (gostaria), ND (não desejo), NU (nunca), AV (às vezes), MU (muito), N (não), B (bate-papo), $\mathrm{P}$ (pesquisa), J (jogos), E (e-mail), V (visitar sites), NAV (navegar), $\mathrm{O}$ (outras finalidades), SR (sem resposta). 


\section{Quadro 1. Funções e Valores Atribuídos ao Computador e à Internet pelos Professores da Escola A $(n=22)$}

\begin{tabular}{|l|l|l|c|}
\hline & \multicolumn{1}{|c|}{ COMPUTADOR } & \multicolumn{1}{|c|}{ INTERNET } & \\
\hline $\mathbf{F}$ & Ferramenta: 11 & Fonte de informações (Pesquisa): 10 & $\mathbf{F}$ \\
$\mathbf{U}$ & Máquina de escrever: 2 & Meio de Comunicação: 5 & $\mathbf{N}$ \\
$\mathbf{C}$ & Diversão: 1 & Diversão: 2 & $\mathbf{C}$ \\
$\mathbf{A}$ & & Ferramenta: 2 & $\mathbf{A}$ \\
$\mathbf{O}$ & & Positivo (rapidez, comodidade): 4 & $\mathbf{\text { V }}$ \\
\hline $\mathbf{V}$ & Positivo (necessidade, rapidez, facilita- & $\mathbf{A}$ \\
$\mathbf{A}$ & dor, evolução, desafio, motivação): 10 & Sem resposta: 1 & $\mathbf{L}$ \\
$\mathbf{L}$ & Sem resposta: 1 & & $\mathbf{R}$ \\
$\mathbf{R}$ & & & \\
\hline
\end{tabular}

"Escola B (Estadual): Atende a alunos do ensino fundamental e médio que provêm, em sua maioria, de famílias com renda baixa. A instituição está equipada com computadores (sem acesso à Internet) que podem ser usados por professores e alunos. Na amostra, constituída de 43 professores, 37 eram do sexo feminino e suas idades variaram de 24 a 59 anos, sendo a idade média aproximadamente igual a 40 anos. $\bigcirc$ tempo de magistério variou de 4 a 35 anos, com maior concentração de professores na faixa de 10 a menos de 20 anos de experiência. Quase todos possuíam Graduação ou Ensino Médio. A maior parte atuava somente no Ensino Fundamental ou no Ensino Fundamental/Médio.

Tabela 2. Resultados das Questões Fechadas do Questionário na Escola $B(n=43)$

\begin{tabular}{|c|c|c|c|c|c|c|c|c|}
\hline Questão & & C & & C P & & D & & \\
\hline 1 & & 2 & & 19 & & 22 & & \\
\hline 2 & & 1 & & 10 & & 32 & & \\
\hline 3 & & 21 & & 22 & & - & & \\
\hline 4 & & 4 & & 32 & & 7 & & \\
\hline 5 & & 5 & & 21 & & 17 & & \\
\hline 6 & & 1 & & 5 & & 37 & & \\
\hline 7 & & 38 & & 5 & & - & & \\
\hline & SO & & ME & & S U & & N L & \\
\hline 8 & 1 & & 15 & & 24 & & 3 & \\
\hline & & S & & G & & N D & & \\
\hline 9 & & 31 & & 12 & & - & & \\
\hline 10 & & 26 & & 17 & & - & & \\
\hline & & N U & & A V & & M & & \\
\hline 11 & & 14 & & 23 & & 6 & & \\
\hline & & S & & N & & S R & & \\
\hline 12 & & 24 & & 15 & & 4 & & \\
\hline & B & P & J & E & V & NAV & O & S R \\
\hline 13 & 3 & 27 & 2 & 12 & 20 & 2 & 3 & 13 \\
\hline
\end{tabular}

Nota: C (concordo), CP (concordo em parte), D (discordo), SO (sólido), ME (mediano), SU (superficial), NL (nulo), S (sim), G (gostaria), ND (não desejo), NU (nunca), AV (às vezes), MU (muito), N (não), B (bate-papo), $P$ (pesquisa), J (jogos), E (e-mail), V (visitar sites), NAV (navegar), $\bigcirc$ (outras finalidades), SR (sem resposta). 


\section{Quadro 2. Funções e Valores Atribuídos ao Computador e à Internet pelos Professores da Escola B $(n=43)$}

\begin{tabular}{|c|l|l|l|}
\hline & \multicolumn{1}{|c|}{ COMPUTADOR } & \multicolumn{1}{|c|}{ INTERNET } & \\
\hline $\mathbf{F}$ & Ferramenta: 20 & Fonte de informações (Pesquisa): 10 & $\mathbf{F}$ \\
$\mathbf{N}$ & Arquivo de dados: 1 & Meio de Comunicação: 10 & $\mathbf{N}$ \\
$\mathbf{C}$ & & Ferramenta: 6 & $\mathbf{C}$ \\
$\mathbf{A}$ & & Diversão: 3 & A \\
$\mathbf{O}$ & & O \\
\hline & Positivo (auxílio, útil, necessidade, & Positivo (comodidade, conhecimento, \\
$\mathbf{V}$ & conhecimento, motivação, desafio): 16 & importante, necessidade, útil, velocidade, & $\mathbf{V}$ \\
$\mathbf{A}$ & Negativo (transtorno, dificuldade, mal & o máximo, novidades, amizades): 13 & $\mathbf{A}$ \\
$\mathbf{L}$ & necessário): 5 & Negativo (transtorno, dificuldade, mal & $\mathbf{L}$ \\
$\mathbf{O}$ & O \\
$\mathbf{R}$ & Sem resposta: 1 & necessário): 5 & $\mathbf{R}$ \\
& & Sem resposta: 1 & \\
\hline
\end{tabular}

- Escola C (Particular): Atende a alunos do ensino fundamental e médio que provêm, em sua maioria, de famílias com renda média ou alta. A instituição está equipada com computadores/Internet que podem ser usados por professores e alunos. $\mathrm{Na}$ amostra, constituída de 31 professores, 15 eram do sexo feminino e suas idades varia- ram de 22 a 56 anos, sendo a idade média aproximadamente igual a 39 anos. $\bigcirc$ tempo de magistério variou de 2 a 33 anos, com maior concentração de professores na faixa de 10 a menos de 20 anos de experiência. A quase totalidade possuía Graduação ou Especialização. A maior parte atuava no Ensino Fundamental/Médio.

Tabela 3. Resultados das Questões Fechadas do Questionário na Escola $C(n=31)$

\begin{tabular}{|c|c|c|c|c|c|c|c|c|}
\hline Questão & & C & & $\mathrm{CP}$ & & D & & \\
\hline 1 & & 3 & & 10 & & 18 & & \\
\hline 2 & & - & & 6 & & 25 & & \\
\hline 3 & & 7 & & 22 & & 2 & & \\
\hline 4 & & 2 & & 24 & & 5 & & \\
\hline 5 & & 1 & & 14 & & 16 & & \\
\hline 6 & & - & & 3 & & 28 & & \\
\hline \multirow[t]{2}{*}{7} & & 29 & & 2 & & - & & \\
\hline & so & & ME & & SU & & NL & \\
\hline \multirow[t]{2}{*}{8} & - & & 23 & & 8 & & - & \\
\hline & & $S$ & & $\mathbf{G}$ & & ND & & \\
\hline 9 & & 31 & & - & & - & & \\
\hline \multirow{2}{*}{10} & & 31 & & - & & - & & \\
\hline & & NU & & AV & & $M$ & & \\
\hline \multirow[t]{2}{*}{11} & & - & & 15 & & 16 & & \\
\hline & & $S$ & & $\mathbf{N}$ & & SR & & \\
\hline \multirow[t]{2}{*}{12} & & 3 & & 28 & & - & & \\
\hline & B & $\mathbf{P}$ & $\mathrm{J}$ & $E$ & $\mathbf{V}$ & NAV & 0 & SR \\
\hline 13 & 2 & 27 & 1 & 23 & 18 & 5 & 1 & - \\
\hline
\end{tabular}

Nota: C (concordo), CP (concordo em parte), D (discordo), SO (sólido), ME (mediano), SU (superficial), NL (nulo), S (sim), G (gostaria), ND (não desejo), NU (nunca), AV (às vezes), MU (muito), N (não), B (bate-papo), $P$ (pesquisa), J (jogos), E (e-mail), V (visitar sites), NAV (navegar), O (outras finalidades), SR (sem resposta). 


\section{Quadro 3. Funções e Valores Atribuídos ao Computador e à Internet pelos Professores da Escola C ( $n=31)$}

\begin{tabular}{|c|c|c|c|}
\hline & COMPUTADOR & INTERNET & \\
\hline \begin{tabular}{|c|}
$\mathbf{F}$ \\
U \\
$\mathbf{N}$ \\
$\mathbf{C}$ \\
$\tilde{A}$ \\
$\mathbf{O}$
\end{tabular} & $\begin{array}{l}\text { Ferramenta: } 20 \\
\text { Máquina de escrever: } 1 \\
\text { Diversão: } 1\end{array}$ & $\begin{array}{l}\text { Fonte de informações (Pesquisa): } 18 \\
\text { Ferramenta: } 8 \\
\text { Meio de Comunicação: } 5 \\
\text { Diversão: } 2\end{array}$ & $\begin{array}{l}\mathbf{F} \\
\mathbf{U} \\
\mathbf{N} \\
\mathbf{C} \\
\mathrm{A} \\
\mathbf{O}\end{array}$ \\
\hline \begin{tabular}{|l|}
$\mathbf{V}$ \\
$\mathbf{A}$ \\
$\mathbf{L}$ \\
$\mathbf{O}$ \\
$\mathbf{R}$
\end{tabular} & $\begin{array}{l}\text { Positivo (facilitador, avanço, moderni- } \\
\text { zação, imprescindível): } 10 \\
\text { Sem resposta: } 1\end{array}$ & $\begin{array}{l}\text { Positivo (facilitador, comodidade, in- } \\
\text { tegração): } 5 \\
\text { Sem resposta: } 1\end{array}$ & $\begin{array}{l}\mathbf{V} \\
\mathbf{A} \\
\mathbf{L} \\
\mathbf{O} \\
\mathbf{R}\end{array}$ \\
\hline
\end{tabular}

"Escola D (Municipal): Atende a alunos do ensino fundamental que provêm, em sua maioria, de famílias com renda baixa. A instituição está equipada com computadores/ Internet que não estão disponíveis para professores e alunos (apenas para uso administrativo). Na amostra, constituída de 24 professores, 22 eram do sexo feminino e suas idades variaram de 24 a 56 anos, sendo a idade média aproximadamente igual a 36 anos. $\bigcirc$ tempo de magistério variou de 6 a 24 anos, com maior concentração de professores com menos de 10 anos de experiência. A grande maioria possuía Graduação ou Ensino Médio. A maior parte atuava somente no Ensino Fundamental.

Tabela 4. Resultados das Questões Fechadas do Questionário na Escola $D(n=24)$

\begin{tabular}{|c|c|c|c|c|c|c|c|c|}
\hline Questão & & C & & CP & & D & & \\
\hline 1 & & - & & 7 & & 17 & & \\
\hline 2 & & - & & 10 & & 14 & & \\
\hline 3 & & 11 & & 12 & & 1 & & \\
\hline 4 & & 1 & & 17 & & 6 & & \\
\hline 5 & & 3 & & 9 & & 12 & & \\
\hline 6 & & - & & 3 & & 21 & & \\
\hline 7 & & 24 & & - & & - & & \\
\hline & SO & & ME & & SU & & NL & \\
\hline 8 & 1 & & 7 & & 15 & & 1 & \\
\hline & & S & & G & & ND & & \\
\hline 9 & & 21 & & 3 & & - & & \\
\hline 10 & & 21 & & 3 & & - & & \\
\hline & & NU & & AV & & M & & \\
\hline 11 & & 5 & & 13 & & 6 & & \\
\hline & & S & & N & & SR & & \\
\hline 12 & & 12 & & 12 & & - & & \\
\hline & B & P & J & E & V & NAV & O & SR \\
\hline 13 & 3 & 19 & 3 & 15 & 16 & 3 & - & 3 \\
\hline
\end{tabular}

Nota: C (concordo), CP (concordo em parte), D (discordo), SO (sólido), ME (mediano), SU (superficial), NL (nulo), S (sim), G (gostaria), ND (não desejo), NU (nunca), AV (às vezes), MU (muito), N (não), B (bate-papo), $\mathrm{P}$ (pesquisa), J (jogos), E (e-mail), V (visitar sites), NAV (navegar), O (outras finalidades), SR (sem resposta). 


\section{Quadro 4. Funções e Valores Atribuídos ao Computador e à Internet pelos Professores da Escola D ( $n=24)$}

\begin{tabular}{|l|l|l|l|}
\hline & \multicolumn{1}{|c|}{ COMPUTADOR } & \multicolumn{1}{|c|}{ INTERNET } & \\
\hline $\mathbf{F}$ & Ferramenta: 18 & Fonte de informações (Pesquisa): 10 & $\mathbf{F}$ \\
$\mathbf{N}$ & & Diversão: 6 & $\mathbf{N}$ \\
$\mathbf{C}$ & & Ferramenta: 5 & $\mathbf{C}$ \\
$\mathbf{A}$ & & Meio de Comunicação: 4 & $\mathbf{A}$ \\
$\mathbf{O}$ & & Positivo (facilitador, comodidade, in- & $\mathbf{V}$ \\
\hline $\mathbf{V}$ & Positivo (auxílio, útil, fantástico, neces- & $\mathbf{A}$ \\
$\mathbf{A}$ & sário, praticidade, comodidade): 11 & tegração): 5 & $\mathbf{L}$ \\
$\mathbf{L}$ & Negativo (não gosto): 1 & Negativo (péssimo): 1 & $\mathbf{0}$ \\
$\mathbf{O}$ & Reg \\
$\mathbf{R}$ & Sem resposta: 1 & Sem resposta: 1 & \\
\hline
\end{tabular}

\section{Discussão dos resultados}

Em todas as escolas, a maioria dos docentes discordou que o computador nunca falhe (questão 1). Essa posição foi observada com maior freqüência na escola federal e na particular. Por outro lado, na estadual, quase metade dos professores concordou ou concordou em parte; um grande número de docentes (exceto na escola municipal) discordou que lidar com computadores cause medo (questão 2) e, apenas na estadual, alguns concordaram; nas escolas federal, estadual e municipal, aproximadamente metade dos docentes concordou que utilizar computadores desenvolva a inteligência (questão 3), mas na escola particular a grande maioria concordou em parte; em geral, os professores concordaram ou concordaram em parte, principalmente nas escolas estadual e particular, que usar o computador isola as pessoas (questão 4); cerca de metade dos professores das escolas federal, particular e municipal discordou que seja muito difícil lidar com computadores (questão 5), ao passo que na estadual essa proporção foi menor. Um número muito expressivo de docentes discordou que o computador possa substituir o professor em um ambiente de aprendizagem (questão 6); nesse sentido, quase todos concordaram que o computador é uma ferramenta a mais para auxiliar o trabalho do professor (questão 7).

conhecimento sobre computadores e Internet (questão 8) foi reconhecido como mediano pela maioria dos docentes das escolas federal e particular (nenhum reconheceu ter conhecimento nulo), enquanto que para os outros professores este foi, de maneira geral, visto como superficial; a existência de computador na residência (questão 9) e a possibilidade de acesso à Internet (questão 10) foram confirmadas por grande parte dos docentes, exceto na escola estadual em que um número considerável não possuía (todos os que não tinham, gostariam de possuir); com relação à freqüência de uso da Internet (questão 11), nas escolas federal e particular mais da metade dos professores utilizava muito e, no caso das demais, mais da metade usava às vezes (na escola estadual, um número expressivo nunca usava); a dificuldade em usar a Internet (questão 12) foi admitida por metade ou mais dos professores das escolas estadual e municipal. Nas outras, a situação foi bem diferente, com grande parte negando tal dificuldade; as 
finalidades de uso da Internet (questão 13) mais indicadas foram: pesquisar, mandar/ receber e-mail, visitar sites, nessa ordem.

No que se refere ao significado do computador e da Internet (questão 14), identificamos, a partir das respostas dadas pelos professores, a atribuição de uma função e/ou de um valor a tais tecnologias (Quadros 1, 2, 3 e 4). Em todas as escolas, a função mais associada ao computador foi a de ferramenta. No caso da Internet, a função mais citada foi: fonte de informações (escolas federal, particular e municipal); na escola estadual, fonte de informações e meio de comunicação foram igualmente citados. As funções de ferramenta e de meio de diversão foram atribuídas, porém com uma freqüência menor.

Os valores identificados nas respostas dos docentes foram, na grande maioria dos casos, considerados positivos: "O computador hoje é uma necessidade para nós professores [...]"; "O computador é uma ferramenta que auxilia no meu trabalho[...]"; "o computador se tornou imprescindível [...]"; "é uma 'máquina de escrever' de última geração [...]"; "para mim o computador é extremamente útil [...]"; "Uma ferramenta que facilita a vida [...]"; "A Internet é um importante meio de comunicação $[\ldots]^{\prime \prime}$; "Acho a Internet o máximo!"; "A Internet para mim é uma excelente fonte de informações [...]."

Apenas nas escolas estadual e municipal, um pequeno número de professores atribuiu valores que foram percebidos como negativos: "Um 'mal' necessário [...]"; "Um transtorno devido à falta de tempo [...]"; "Não gosto de trabalhar com ele $[. .$.$] "; "A Internet é um péssimo meio$ de comunicação."

Quanto ao uso do computador e/ou da Internet na prática pedagógica (Questão 15), pode-se observar, na Tabela 5, que a freqüência de utilização variou bastante: nas escolas particular e federal quase todos os professores utilizavam; na municipal, cerca de $2 / 3$ utilizavam; já na estadual, mais da metade não usava.

\section{Tabela 5. Utilização do computador e/ou da Internet pelos professores das escolas A, B, C e D}

\begin{tabular}{|c|c|c|}
\hline Escola & Utiliza & Não utiliza \\
\hline A & 18 & 4 \\
\hline B & 19 & 24 \\
\hline C & 30 & 1 \\
\hline D & 15 & 9 \\
\hline
\end{tabular}

As formas de utilização das tecnologias, mencionadas pelos docentes, encontram-se descritas no Quadro 5. 


\section{Quadro 5. Formas de Utilização do Computador e/ou da Internet pelos Professores das Escolas A, B, C e D}

\begin{tabular}{|c|l|l|c|}
\hline ESCOLA & \multicolumn{1}{|c|}{ COMPUTADOR } & INTERNET & ESCOLA \\
A & $\begin{array}{l}\text { Uso de aplicativos: 6 } \\
\text { Digitação de trabalhos e provas: 5 } \\
\text { Uso de softwares educacionais: 2 } \\
\text { Digitação de trabalhos pelos alunos: 1 }\end{array}$ & $\begin{array}{l}\text { Pesquisa realizada pelos alunos: 8 } \\
\text { Pesquisa realizada pelo professor: 6 } \\
\text { E-mail: 2 }\end{array}$ & A \\
\hline B & Digitação de trabalhos e provas: 10 & Pesquisa realizada pelo professor: 17 & B \\
\hline C & $\begin{array}{l}\text { Digitação de trabalhos e provas: 18 } \\
\text { Uso de softwares educacionais: 3 } \\
\text { Uso de aplicativos: 2 } \\
\text { Produção de jogos: 1 } \\
\text { Digitação de trabalhos pelos alunos: 1 }\end{array}$ & $\begin{array}{l}\text { Pesquisa realizada pelo professor: 22 } \\
\text { E-mail: 6 } \\
\text { Visitas a sites: 4 } \\
\text { Listas de discussão: 1 } \\
\text { Pesquisa realizada pelos alunos: 1 }\end{array}$ & C \\
\hline D & Digitação de trabalhos e provas: 11 & $\begin{array}{l}\text { Pesquisa realizada pelo professor: 12 } \\
\text { Visitas a sites: 2 } \\
\text { E-mail: 1 }\end{array}$ & D \\
\hline
\end{tabular}

Observa-se que nas escolas estadual e municipal o computador era usado apenas para digitação de trabalhos e de provas, ou seja, com a finalidade de "máquina de escrever". Nas outras escolas, embora o uso fosse mais diversificado, parte dos professores também só o empregava como "máquina de escrever". A Internet era mais freqüentemente utilizada com a finalidade de os professores realizarem pesquisas, excetuando-se a escola federal em que a pesquisa, com o auxílio da rede, era feita pelos alunos, bem como pelos professores. Tal como no caso do computador, verifica-se um uso mais diversificado da Internet nas escolas particular e federal.

Os docentes alegaram os seguintes motivos para não utilizar o computador e/ou a Internet:

Escola Federal: falta de tempo, de infraestrutura da escola (conflito de horários para todas as turmas usarem o laboratório de informática), de iniciativa e de conhecimento, além de custo da linha telefônica.

Escola Estadual: falta de acesso, de preparo, de tempo, de iniciativa, de condições financeiras e de interesse.

Escola Particular: falta de preparo e de tempo.

Escola Municipal: falta de acesso e de interesse.

Dentre os motivos alegados para a não utilização do computador e/ou da Internet, destaca-se a falta de acesso dos docentes das escolas estadual e municipal a essas tecnologias. Além disso, na escola estadual, alguns professores admitiram falta de preparo. $\bigcirc$ fato de parte considerável desses professores não ter acesso às tecnologias, implica em não terem familiaridade com as mesmas e desconhecerem suas possibilidades de utilização. 


\section{Considerações Finais}

A partir dos resultados obtidos com a aplicação do questionário, observamos que:

(a) A tendência a mitificar o computador parece ser maior entre os docentes da escola estadual;

(b) $\bigcirc$ computador não parece causar medo, exceto para uma parcela dos professores da escola municipal;

(c) A dificuldade em lidar com o computador é mais reconhecida entre os docentes das escolas estadual e municipal;

(d) $\bigcirc$ computador é visto, de maneira geral, como um aliado e não como uma ameaça;

(e) $O$ conhecimento alegado sobre computadores e Internet é maior entre os professores das escolas federal e particular;

(f) A possibilidade de acesso ao computador e à Internet é menor para os docentes das escolas estadual e municipal;

(g) Há indícios de que os professores desejam ter acesso às tecnologias;

(h) A freqüência de uso da Internet é maior entre os professores das escolas federal e particular (na escola estadual, muitos afirmam nunca usar);

(i) A dificuldade em utilizar a Internet é mais admitida por professores das escolas estadual e municipal;

(i) A Internet é mais usada para pesquisar, mandar/receber e-mail e visitar sites, atividades que envolvem busca de informações e de comunicação (com possível troca de informações). As opções que envolvem finalidades de lazer (bate-papo, jogos) foram muito menos apontadas pelos docentes;

(k) A função mais associada ao computador foi a de ferramenta e, a Internet, foi vista, principalmente, como fonte de informações e meio de comunicação;

(I) Os valores atribuídos às tecnologias foram, na grande maioria dos casos, positivos;

(m) $\bigcirc$ uso das tecnologias na prática pedagógica parece ser mais freqüente e di- versificado nas escolas particular e federal;

(n) A falta de acesso foi o motivo mais alegado para a não utilização das tecnologias pelos docentes das escolas estadual e municipal.

Embora as pesquisas tenham abrangências muito diferentes, observamos que parte dos resultados alcançados pelo estudo em questão tem semelhança com aqueles obtidos no já mencionado estudo realizado pela Unesco. Principalmente, devemos ressaltar a falta de acesso dos professores às tecnologias, resultando em não familiaridade e despreparo para sua utilização na prática pedagógica.

Acreditando que os resultados do estudo possam ser indicações denotativas do imaginário social do magistério em relação às tecnologias de informação, podemos inferir que a rejeição que parecia haver por parte dos professores às novas tecnologias vem diminuindo: o computador foi considerado uma ferramenta para apoiar o trabalho docente e, a Internet, uma fonte de informações (usada, principalmente, para pesquisas), bem como um meio de comunicação.

A partir dos dados levantados, há indícios de que:

- Os professores de escolas estaduais e municipais têm maior dificuldade em lidar com as $\mathrm{TI}$, bem como menor possibilidade de acesso;

- Há relação entre o tipo de escola em que o professor atua e a utilização das TI como recurso pedagógico.

Uma questão decorre do que foi investigado: o que os professores denominam "fazer pesquisa" quando utilizam a Internet?

Essa e outras questões serão objeto de análise de pesquisa futura, que terá como sujeitos, docentes e discentes do ensino superior público e privado. 


\section{ABSTRACT \\ The meaning of reproduction technologies for educators}

This qualitative/quantitative research attempted to investigate the perceptions of teachers in relation to technologies of information (TI), especially computers and Internet. It is a continuation of a previous research, which tried to identify the meaning of $\mathrm{TI}$ to students. The data, gathered from 556 students, revealed that they long to deal with TI for they consider the computer a learning tool and the Internet, a source of communication and research.

This study, which involved 120 teachers of both private and public schools, pointed out that they consider the computer an ally, not a menace, to their profession. The research showed that there seems to be a relationship between the kind of school in which the teacher works and the use of $\mathrm{Tl}$ in pedagogical practice. There are hints that the rejection towards new technologies, which seemed to exist among teachers, has decreased. Keywords: Education. Technologies of Information. Educational Psychology.

\section{RESUMEN \\ El significado de las tecnologías de la información para los educadores}

La investigación descrita de naturaleza cuantitativa y cualitativa tuvo como objetivo investigar las percepciones docentes con relación a las tecnologías de información (TI), específicamente la computadora y la Internet. Se trata de una continuación de un estudio anterior, que buscó identificar el significado de las TI para los alumnos. Los datos obtenidos junto a 556 alumnos revelaron que éstos, además de querer utilizar las TI en su aprendizaje, consideraban la computadora como una herramienta, y la Internet, un instrumento de comunicación y investigación.

En este estudio, con 120 profesores de escuelas públicas y privadas, encontramos indicadores de que la computadora es considerada un aliado y no una amenaza con relación a la profesión docente. También se constató que parece tener relación entre el tipo de escuela en que actúa el profesor y la utilización de las TI en la práctica pedagógica. Hay indicios de que el rechazo que parecía existir por parte del magisterio a las nuevas tecnologías esta disminuyendo.

Palabras-clave: Educación. Tecnologías de Información. Sicología de la Educación. 


\section{Referências bibliográficas}

ALAVA, S. et al. (Col.). Ciberespaço e formações abertas: rumo a novas práticas educacionais? Tradução de Fátima Murad. Porto Alegre: Artmed, 2002.

ALMEIDA, M. E. Informática e formação de professores. Brasília, DF: MEC, Secretaria de Educação a Distância, 2000. v. 1.

AZEVEDO, N. O imaginário social e a metacognição. In: MALUF, U. (Org.). Epistemologias não-ordinárias: paradigmas alternativos em ciências humanas e sociais. Rio de Janeiro: Booklink, 2003.

BARDIN, L. Análise de conteúdo. Lisboa: Edições 70, 1977.

BATTRO, A. M.; DENHAM, P. J. La educación digital. Buenos Aires: Emecé, 1997.

CASTORIADIS, C. A instituição imaginária da sociedade. Rio de Janeiro: Paz e Terra, 1991.

FRANCO, M. A. Ensaio sobre as tecnologias digitais da inteligência. Campinas, SP: Papirus, 1997.

HACKBARTH, S. Integrating web-based learning activities into school curriculums. Educational Technology, New Jersey, v. 37, n. 3, p. 59-66, 1997.

LÉVY, P. As inteligências coletivas. São Paulo: SESC, 2002. Disponível em: < http:// www.sescsp.org.br>. Acesso em: mar. 2003.

. Cybercultura. Rio de Janeiro: Ed.34, 1999.

. Les technologies de l'intelligence: I'avenir de la pensée à l'ere informatique. Paris: La Découvert, 1993.

MACHADO, N. J. Epistemologia e didática. São Paulo: Cortez, 1995.

MADDUX, C. D. The internet: educational prospects and problems. Educational Technology, New Jersey, v. 34, n. 9, p. 37-42, 1994.

MEDEIROS, L. Professores desplugados. O Globo, Rio de Janeiro, p. 6, 23 maio 2004.

MORAN, J. M. Ensino e aprendizagem inovadores com tecnologias audiovisuais e telemáticas. In: MORAN, J. M. (Org.). Novas tecnologias e mediação pedagógica. Campinas, SP: Papirus, 2000. 
MORAN, J. M. Mudanças na comunicação pessoal: gerenciamento integrado da comunicação pessoal, social e tecnológica. São Paulo: Paulinas, 1998.

OLIVEIRA, R. Informática educativa. Campinas, SP: Papirus Editora, 1997.

PALLOFF, R. M.; PRATT, K. Construindo comunidades de aprendizagem no ciberespaço. Porto Alegre: Artmed, 2002.

PERRENOUD, P. Dez novas competências para ensinar. Porto Alegre: Artmed, 2000.

SILVA, C. M. T. Avaliação dos efeitos da utilização da hipermídia na educação. In: ALVARENGA, G. M. (Org.). Avaliar: um compromisso com o ensino e a aprendizagem. Londrina, PR: Núcleo de Estudos e Pesquisas em Avaliação Educacional, 1999. p. 111-137.

- Hipermídia na educação: desenvolvimento e abordagem alternativa para avalia$\overline{c ̧ a ̃ o ~ d e ~ q u a l i d a d e ~ e ~ e f e i t o s . ~ 1997 . ~ T e s e ~(D o u t o r a d o ~ e m ~ E n g e n h a r i a ~ d e ~ P r o d u c ̧ a ̃ o)-C o o r d e-~}$ nação dos Programas de Pós-Graduação em Engenharia, Universidade Federal do Rio de Janeiro, Rio de Janeiro, 1997.

SILVA, C. M. T.; AZEVEDO, N. S. N. Mudanças na formação de professores: proposta de estratégia em relação às tecnologias de informação e comunicação. Ensaio: avaliação e políticas públicas em educação, Rio de Janeiro, v. 9, n. 31, p.193-204, abr./jun. 2001.

O significado das tecnologias de informação para educandos: pistas para a cooperação e a autonomia em ambientes de aprendizagem. Ensaio: avaliação e políticas públicas em educação, Rio de Janeiro, v.11, n. 38, p.121-133, jan./mar. 2003.

SILVA, C. M. T.; ELLIOT, L.G. Avaliação da hipermídia para uso em educação: uma abordagem alternativa. Revista Brasileira de Estudos Pedagógicos, Brasília, DF, v. 78, n. 188/ 189/190, p. 262-284, 1998.

Avaliação de software educacional hipermídia: a contribuição de especialistas e usuários. Ensaio: avaliação e políticas públicas em educação, Rio de Janeiro, v. 5, n. 16, p. 299-312, jul./set. 1997.

VALENTE, J. A. Diferentes usos do computador na educação. In: VALENTE, J. A. (Org.). Computadores e conhecimento: repensando a educação. Campinas, SP: Gráfica Central da Unicamp, 1998. p. 1-27.

VYGOTSKY, L. Pensamento e linguagem. São Paulo: Martins Fontes, 1987.

WALLON, H. As origens do caráter da criança. São Paulo: Nova Alexandria, 1995.

\section{Correspondência:}

chrismts@rio.com.br

nazavedo@alternex.com.br 


\section{ANEXO}

Professor(a): Por favor, preencha este questionário. Isto é muito importante para que possamos conhecêlo(a) melhor. As informações prestadas por você servirão de subsídio à pesquisa realizada por professoras da Faculdade de Educação da UFRJ.

Idade: Sexo: ( ) M( ) F

\section{Escolaridade:}

( ) Ensino Médio ( ) Graduação ( ) Especialização ( ) Mestrado ( ) Doutorado Tempo de Magistério:

Níveis de ensino em que leciona: ( ) Fundamental ( ) Médio ( ) Superior Atenção: Nos itens de 1 a 13 assinale apenas a opção de sua preferência.

1. $O$ computador é uma máquina que nunca falha.
( ) concordo
( ) concordo em parte
( ) discordo

2. Lidar com computadores é uma atividade que causa medo.
( ) concordo
( ) concordo em parte
( ) discordo

3. Utilizar computadores desenvolve a inteligência.
( ) concordo
( ) concordo em parte
( ) discordo

4. Usar o computador é uma atividade que isola as pessoas.
( ) concordo
( ) concordo em parte
( ) discordo

5. É muito difícil lidar com computadores.
( ) concordo
( ) concordo em parte
( ) discordo

6. O computador pode substituir o professor num ambiente de aprendizagem.
( ) concordo
( ) concordo em parte
( ) discordo

7. $O$ computador é uma ferramenta a mais para auxiliar o trabalho do professor.
( ) concordo
( ) concordo em parte
( ) discordo

8. Como você classificaria o seu conhecimento sobre computadores e Internet?
( ) sólido
( ) mediano
( ) superficial
( ) nulo

9. Você possui um computador em sua residência?

( ) sim ( ) não, mas gostaria de possuir ( ) não desejo possuir

10. Você possui acesso à Internet?

( ) $\operatorname{sim}($ ) não, mas gostaria de possuir ( ) não desejo possuir

11. Com que freqüência você utiliza a Internet?

( ) nunca ( ) às vezes ( ) muito

12. Você sente dificuldade em usar a Internet?

( ) $\operatorname{sim}($ ) não

13. Com que finalidades você usa a Internet?

( ) bate-papo ( ) pesquisa ( ) jogos ( ) mandar/receber e-mail ( ) visitar sites

( ) navegar sem rumo ( ) outras finalidades. Quais?

14. O que o computador significa para você? E a Internet?

15. Você utiliza o computador e/ou a Internet em sua prática pedagógica?

( ) $\operatorname{sim}($ ) não

Explique como utiliza.

Explique por que não utiliza. 